\title{
lodine Status of Pregnant Women and Their Progeny in the Minho Region of Portugal
}

\author{
Maria J. Costeira, ${ }^{1,2}$ Pedro Oliveira, ${ }^{1,3}$ Susana Ares, ${ }^{4}$ Gabriella Morreale de Escobar, ${ }^{4}$ and Joana A. Palha ${ }^{1}$
}

Background: Iodine sufficiency is particularly necessary throughout pregnancy, given its recognized impact on psychomotor performance of the offspring. There are no recent reports about iodine status or supplementation in Portugal, a country that the International Council for Control of Iodine Deficiency Disorders considered, in 2004, to have probably reached iodine sufficiency. The objective of this study was to evaluate in the Minho region of Portugal the iodine status of women throughout pregnancy and after delivery, and of their offspring.

Methods: Urinary iodine concentration (UI) was determined in 78 nonpregnant premenopausal women, in 140 pregnant women in the three trimesters of pregnancy and after delivery, and in their 142 offspring. Milk iodine concentration was determined at day 3 and 3 months after delivery. The thyroid volume was determined in women in the third trimester of pregnancy and 3 months after delivery and in infants at 3 months of age.

Results: Based on the World Health Organization criteria, both nonpregnant and pregnant women had iodine deficiency (ID), as documented by median UI of $<75 \mu \mathrm{g} / \mathrm{L}$ and milk iodine concentration of $<100 \mu \mathrm{g} / \mathrm{L}$. Goiter was observed in $14 \%$ of the pregnant women. Concordant with the mother's ID, median neonatal UI was low (71 and $97 \mu \mathrm{g} / \mathrm{L}$ at 3 days and 3 months of age).

Conclusion: Portuguese women of the Minho region have an inadequate iodine intake, which may compromise the potential for full psychomotor development of their progeny. These observations suggest that iodine supplementation should be implemented throughout pregnancy and lactation in Portugal.

\section{Introduction}

I ODINE IS A trace element required for the biosynthesis of thyroid hormones and is obtained solely from external sources. Thyroid hormones regulate various processes of cellular metabolism, influencing all cells throughout life. Particularly important is the role of thyroid hormones in normal brain development and cognition. It has been shown that insufficient iodine intake during pregnancy and lactation and in newborns may lead to irreversible brain damage (1-9). The severity of this impairment varies from cretinism, in regions of severe iodine deficiency (ID), to the inability of children to achieve their potential intelligence quotient, when iodine intake is mildly to moderately insufficient. ID is, worldwide and after starvation, the most important preventable cause of mental retardation. Since 1990 it has been accepted as a basic human right that every child has the right to an adequate supply of iodine to ensure its normal development and that every mother has the right to an adequate iodine nutrition to ensure that her unborn child reaches its potential mental development (4). Further, it is believed that iodine-related neurodevelopmental deficits of future generations can be prevented by promoting universal salt iodination and the use of iodine supplements from the onset of pregnancy or when pregnancy is planned (1-9).

The World Health Organization (WHO) urges its member states to assess the extent and severity of ID disorders (IDD), to promote universal salt iodination and to monitor the iodine status of their populations (1-3). In Portugal, there are no recent reports about iodine nutrition, percentage of households with access to iodized salt, or thyroid hormone concentrations and iodine intake in pregnant women (3). In this study, therefore, we aimed to evaluate the iodine nutrition of Portuguese women of fertile age, throughout pregnancy and after delivery. This was done by nutritional questionnaires and measuring iodine concentrations in urine and breast milk, and by determining their thyroid volume, as well

\footnotetext{
${ }^{1}$ Life and Health Sciences Research Institute (ICVS), School of Health Sciences, University of Minho, Braga, Portugal.

${ }^{2}$ Centro Hospitalar do Alto Ave, EPE, Guimarães, Portugal.

${ }^{3}$ Department of Production and Systems Engineering, University of Minho, Guimarães, Portugal.

${ }^{4}$ Instituto de Investigaciones Biomédicas Alberto Sols, Centro Mixto Consejo Superior de Investigaciones Científicas, Universidad Autónoma de Madrid, Madrid, Spain.
} 
as their offspring's urinary iodine concentration (UI), thyroid volume, and neonatal thyroid-stimulating hormone (TSH).

\section{Subjects and Methods}

\section{Subjects}

The study was carried out at the Centro Hospitalar do Alto Ave, EPE (Hospital Sra da Oliveira, Guimarães) and at the School of Health Sciences, University of Minho, Braga. Guimarães and Braga are two cities located $50 \mathrm{~km}$ away from the sea, with both urban and rural populations, in a total of about 0.7 million inhabitants. Between January 2003 and December 2005 we invited 140 pregnant women who were attending the antenatal clinic in Centro Hospitalar do Alto Ave, EPE, to have UI measured during and after pregnancy, as well as thyroid ultrasound scans for thyroid volume. Demographic information and clinical information were collected: age, number of previous pregnancies, use of iodine supplements, current and previous pathologies, and Graffar socioeconomic and cultural status (10). The Graffar scale includes information on the type of work and education of the women and their partners, family income, characteristics of the house, and the type of neighborhood. It provides a scale from I to V: class I corresponds to families with higher education, better jobs, and nicer houses and neighborhood; class V corresponds to those with lower educational status and worst jobs, houses, and neighborhood. A food-frequency questionnaire was used to inquire about the number of fish meals per week, the use of iodized salt and of iodine-containing multivitamin pills, and whether the eating regimen was vegetarian. Exclusion criteria were the use of drugs or of iodinated antiseptics, previous diabetes, assisted medical reproduction, malformations of the fetus, thyroidal and other endocrine dysfunctions, and heavy smoking of more than 10 cigarettes daily.

Permission was given by 140 mothers to enroll their babies in the study. Clinical information was recorded about delivery (gestational age and type of delivery), Apgar score, birth weight, length, and head circumference. A total of 78 nonpregnant healthy women of fertile age, with no pregnancies reported for the previous year, were recruited from the School of Health Sciences, University of Minho, Braga, and from the Centro Hospitalar do Alto Ave, EPE, Guimarães. The same demographic and clinical data as well as exclusion criteria were applied. The study design and procedures were approved by the local research ethics committee. All enrolled women gave written informed consent.

\section{Assessment of iodine status}

Urine samples were collected from pregnant women in each trimester of pregnancy $(12 \pm 1,24 \pm 1$, and $32 \pm 1$ weeks), during labor, and 3 days, 3 months, and 1 year after delivery. One random urine sample was collected from the nonpregnant women. Urine samples from the infants were collected 3 days and 3 months after birth. The urinary samples were collected in the morning and, whenever possible, in the fasting state, in a screw-capped plastic bottle, with no added preservative. Aliquots were stored frozen at $-80^{\circ} \mathrm{C}$ until use. Breast milk was also obtained at 3 days and 3 months after delivery, whenever available. Milk samples were similarly collected and stored. UI was measured by the ammonium persulfate method (1), and milk iodine concentrations were measured by a modification of the chloric acid digestion method (1). Results were expressed as $\mu \mathrm{g} / \mathrm{L}$. Determinations were repeated in samples with values below $50 \mu \mathrm{g} / \mathrm{L}$ or above $300 \mu \mathrm{g} / \mathrm{L}$.

Pregnant women and their progeny had ultrasound examination of the thyroid to determine the thyroid volume and to evaluate the echo texture of the gland. The examination was performed with a real-time Philips HD II instrument (Eindhoven, The Netherlands) with a $7.5 \mathrm{MHz}, 50-\mathrm{mm}$ Gemini linear transducer L12-5. Thyroid volume was calculated as the sum of maximal length $\times$ width $\times$ depth $\times \pi / 6$ of each lobe (isthmus not included) (1). Thyroid volume of the women was assessed in the third trimester of pregnancy and repeated 3-6 months after delivery. The gland was considered enlarged when the volume was $>18 \mathrm{~mL}$, which corresponds to the mean +3 SDs of the volume in iodine-sufficient populations (9). It was classified as goiter when the volume was more than $22 \mathrm{~mL}$ (9). When the echo texture of the gland was not homogeneous, showing small lesions or distinct diffuse abnormalities, it was classified as heterogeneous. Thyroid volume was similarly calculated for infants at 3 months of age.

Information on neonatal TSH concentration was obtained from the National Congenital Hypothyroidism Screening Program that was performed at the Instituto de Genética Médica Dr. Jacinto Magalhães, Porto. TSH measurements were done on blood samples collected between 3 and 6 days after birth by the Delfia (immunofluorescence) method in a Perkin Elmer Trade Mark (Zaventem, Belgium). The cutoff for congenital hypothyroidism was established at $20 \mathrm{mIU} / \mathrm{L}$.

\section{Statistical analyses}

Data are presented as mean $\pm \mathrm{SD}$ or median with interquartile range. For variables exhibiting a skewed distribution, the median was used as the measure of central tendency together with the interquartile range. Logarithmic transformations were also done for these variables. Comparisons were made using the $t$-test or the nonparametric Mann-Whitney test. Correlations between neonatal and maternal variables were performed using the Pearson correlation or Spearman's rank correlation tests. Statistical analyses were performed using the SPSS 15 software package (SPSS, Chicago, IL). Values were considered significant when $p<0.05$. All tests were two sided.

\section{Results \\ Demographic data}

The demographic data of women are presented in Table 1. From the questionnaire, three of the nonpregnant women reported to suffer from epilepsy and two from asthma. With respect to the pregnant women, all were breast-feeding 3 days after delivery and 81 continued for at least 3 months, with no information available in 16 cases. Six of the pregnancies were multiple, and three women became pregnant a second time during the study period. All pregnant women were recruited from a high-risk obstetrical consultation, and had been sent because of previous pathologies: abortion $(n=32)$, hypertension $(n=79)$, and psychological/psychiatric disorders $(n=13)$. In the pregnancy under study, 23 had gestational diabetes and 16 had gestational hypertension. No women reported the use of iodine supplements or of iodized salt or to be vegetarians. Pregnant and nonpregnant women were 
Table 1. Demographic Characteristics of the Women

\begin{tabular}{|c|c|c|}
\hline & $\begin{array}{l}\text { Pregnant } \\
\text { women }\end{array}$ & $\begin{array}{l}\text { Nonpregnant } \\
\text { women }\end{array}$ \\
\hline$n$ & 140 & 78 \\
\hline Age (years) (mean $\pm S D)$ & $30.1 \pm 6.7$ & $29.4 \pm 6.5$ \\
\hline $\begin{array}{l}\text { Previous pregnancies } \\
\quad(\text { mean } \pm \text { SD })\end{array}$ & $2.3 \pm 1.5$ & $1.05 \pm 1.1$ \\
\hline $\begin{array}{l}\text { Medium-high socioeconomic } \\
\text { status (\%) }\end{array}$ & 53.6 & 79.5 \\
\hline \multicolumn{3}{|l|}{ Fish consumption } \\
\hline No. of times/week $($ mean $\pm S D)$ & $1.5 \pm 0.7$ & $1.4 \pm 0.7$ \\
\hline Less than three times/week (\%) & 51.4 & 53.8 \\
\hline
\end{tabular}

similar in age and fish consumption, but were significantly different in the number of previous pregnancies and socioeconomic status $(z=-6.6, p<0.05 ; t=-4.6 ; p<0.05)$.

Table 2 presents information on the newborn babies. Three of the newborns were with very low birth weight $(<1500 \mathrm{~g})$, and 14 low birth weight $(<2500 \mathrm{~g}) ; 3$ were macrosomic $(>4000 \mathrm{~g}$ ), and 29 were admitted to the Neonatology Unit (for prematurity, low birth weight, sepsis, or hyperbilirubinemia), where 1 died.

\section{Urinary and milk iodine}

Table 3 presents the median UI for women and babies and milk iodine, as well as the percentage of individuals within the iodine classes as defined by the WHO $(1-3,11,12)$. Figure 1 depicts the cumulative percentage of women taking into consideration the cutoff of iodine sufficiency for the pregnant population $(>150 \mu \mathrm{g} / \mathrm{L})$ and for the nonpregnant population $(>100 \mu \mathrm{g} / \mathrm{L})(1-3,11,12)$. Nonpregnant women had a median UI of $75 \mu \mathrm{g} / \mathrm{L}$, which is below the median of $100 \mu \mathrm{g} / \mathrm{L}$ expected for the general population in an iodine-sufficient population (1-3,11-13). UI did not correlate with women's age, parity, socioeconomic status, or fish consumption. However, when comparing women with $\mathrm{U}<50 \mu \mathrm{g} / \mathrm{L}$ with those with $\mathrm{UI} \geq 50 \mu \mathrm{g} / \mathrm{L}$, the lower UI was associated with lower socioeconomic status $(t=2.2, p<0.05)$ and more pregnancies $(t=2.7, p<0.05)$.

Pregnant women also displayed UI below those recommended for pregnancy. After delivery and lactation, UI was still lower than the recommended values. Notably, women had lower UI 1 year after delivery than throughout pregnancy. A comparison made at the first trimester of pregnancy between women with UI below $(n=52)$ and above $(n=84) 50 \mu \mathrm{g} / \mathrm{L}$ indicated that the lower UI were from women

Table 2. Demographic Characteristics of the Progeny

\begin{tabular}{lc}
\hline$n$ & 142 \\
Sex: girls/boys & $66 / 76$ \\
Gestational age (weeks) (mean \pm SD) & $37.9 \pm 2.0$ \\
Type of delivery & \\
$\quad$ Cesarean & $43.7 \%$ \\
$\quad$ Vaginal & $56.3 \%$ \\
Birth weight $(\mathrm{g})($ mean \pm SD) & $3111 \pm 514$ \\
Length at birth (cm) (mean \pm SD) & $48.5 \pm 2.4$ \\
Head circumference (cm) (mean \pm SD) & $34.2 \pm 1.5$ \\
Apgar score at 1 min (mean \pm SD) & $8.8 \pm 0.9$ \\
Apgar score at 5 min (mean \pm SD) & $9.8 \pm 0.8$ \\
\hline
\end{tabular}

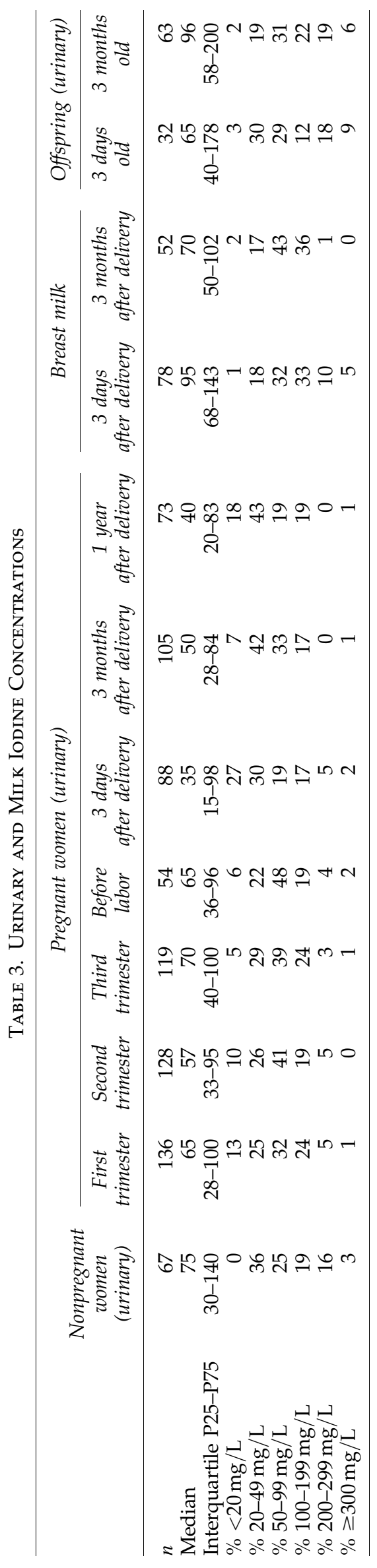


FIG. 1. Cumulative percentage of women, taken into consideration the cutoff of urinary iodine (UI) concentration sufficiency for pregnant $(>150 \mu \mathrm{g} / \mathrm{L})$ and nonpregnant $(>100 \mu \mathrm{g} / \mathrm{L})$ women.

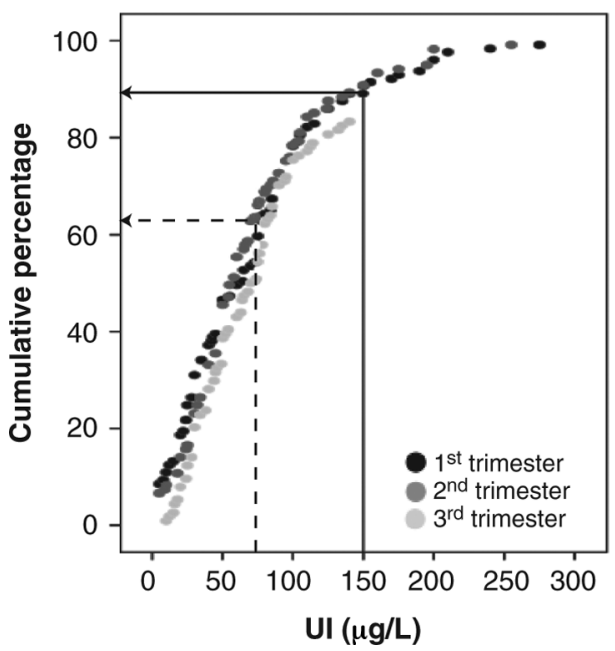

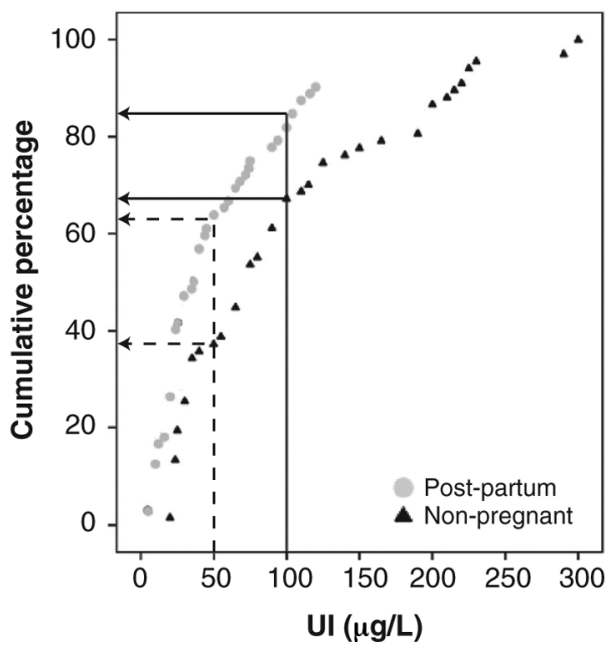

with a lower socioeconomic status $(t=3.0, p<0.05)$. No statistically significant differences were found when age, parity, or fish consumption were considered.

There was no correlation between UI during or after pregnancy and women's age or parity. There was a weak negative correlation between UI in the third trimester and socioeconomic status $(R=-0.200, p<0.05)$. In pregnant women there was also a weak correlation between fish consumption and age $(R=0.245, p<0.01)$, and a negative correlation between fish consumption and socioeconomic status $(R=-0.266$, $p<0.01)$. When UI of women after delivery was considered in relation to breast-feeding no differences were found. Three months after delivery, women breast-feeding $(n=55)$ had median UI of $46 \mu \mathrm{g} / \mathrm{L}$, while the formula-feeding ones $(n=36)$ had median UI of $49 \mu \mathrm{g} / \mathrm{L}$.

Breast milk iodine was also below the recommended values of $150-180 \mu \mathrm{g} / \mathrm{L}(4,14)$, with a median of $95 \mu \mathrm{g} / \mathrm{L}$ at 3 days and of $70 \mu \mathrm{g} / \mathrm{L}$ at 3 months after delivery. Iodine in breast milk

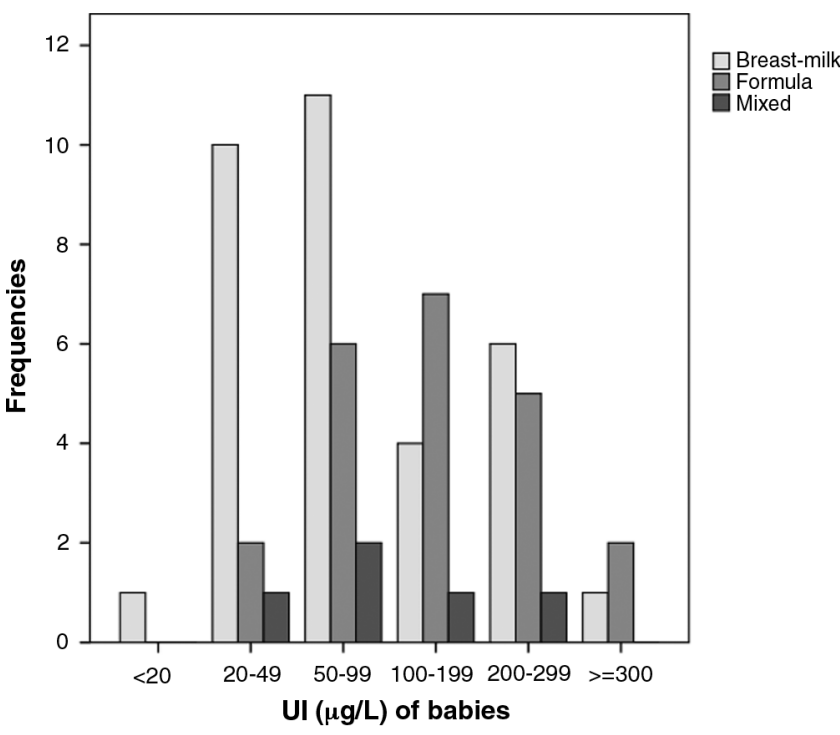

FIG. 2. Percentage of babies with UI concentration, as defined by the World Health Organization, according to the type of feeding. correlated with UI at 3 days $(R=0.440, p<0.01)$ and 3 months ( $R=0.456, p<0.01)$ after delivery. There were no correlations between iodine in breast milk and women's parity, fish consumption, socioeconomic class, thyroid volume 3 months after pregnancy (see thyroid volume section), gestational age, or birth weight of the newborn.

Median UI of the progeny measured both at 3 days and at 3 months were below that accepted for iodine sufficiency (1-3). When comparing the UI of 3-day-old and 3-month-old babies by paired samples tests $(n=20)$, there was a trend for UI to increase with age (median of $70 \mathrm{vs.} 103 \mu \mathrm{g} / \mathrm{L}$, respectively), but this did not reach statistical significance. At 3 months the median UI of the babies $(n=64)$ was $96 \mu \mathrm{g} / \mathrm{L}$. Notably, when grouped according to their mode of feeding (Fig. 2), those on formulas $(n=24)$ had a median UI of $137 \mu \mathrm{g} / \mathrm{L}$, on breast milk $(n=34)$ a median UI of $80 \mu \mathrm{g} / \mathrm{L}$, and on both formula and breast milk $(n=6)$ a median UI of $93 \mu \mathrm{g} / \mathrm{L}$, with these differences being statistically significant $(z=-2.5, p<0.05)$. We did not find differences in neonatal TSH or thyroid volume in babies related to their mode of feeding.

There was no relationship between the babies' UI either at 3 days or at 3 months of gestational age and birth weight, type of delivery, neonatal TSH, or neonatal thyroid volume (see below), or with the mother's age, socioeconomic status, parity, or fish consumption.

\section{Thyroid volume}

The mean thyroid volume in the third trimester was $14.8 \pm 4.7 \mathrm{~mL}$. Twenty-three percent of the women had an enlarged gland $(>18 \mathrm{~mL}), 13.8 \%$ had goiter $(>22 \mathrm{~mL})$, and $12.6 \%$ had heterogeneity of their ultrasound pattern. The corresponding mean value for thyroid volume 3 months after delivery was $11.9 \pm 5.3 \mathrm{~mL}$. Thyroid enlargement was noted in $14.5 \%$, and $5.8 \%$ had goiter. Heterogeneity was noted in $23.3 \%$. The mean thyroid volume in babies at 3 months of age was $0.6 \pm 0.4 \mathrm{~mL}$.

There was no correlation between thyroid volume of the mothers either during or after pregnancy and age, parity, socioeconomic status, or UI. There was a weak negative correlation between thyroid volume in the third trimester and fish consumption $(R=-0.255, p<0.05)$, but this was not noted 3 months after delivery. Thyroid volume in the third 
trimester correlated positively with thyroid volume 3 months after delivery $(R=0.478, p<0.01)$. Thyroid volume in babies did not correlate with their gestational age, birth weight, neonatal TSH, or UI at 3 days or 3 months. The percentage of babies with thyroid volume above the 75th percentile, adjusted for age, sex, and body surface area, was 16.2.

\section{Neonatal TSH}

In 117 newborns mean neonatal TSH was $1.6 \pm 1.2 \mathrm{mUI} / \mathrm{L}$. Only one baby had a TSH $>5 \mathrm{mUI} / \mathrm{L}$, and the percentile $75 \mathrm{th}$ was $2.1 \mathrm{mUI} / \mathrm{L}$. The neonatal TSH did not correlate with the babies' gestational age, birth weight, thyroid volume, or UI collected at 3 days or 3 months. There were no differences in the neonatal TSH, UI, or thyroid volume in babies born of women $(n=34)$ with UI of $<50 \mu \mathrm{g} / \mathrm{L}$ in the third trimester of pregnancy compared to those born of women $(n=65)$ with UI of $\geq 50 \mu \mathrm{g} / \mathrm{L}$ during a similar period of pregnancy.

\section{Correlations mothers-progeny}

The UI, neonatal TSH, and thyroid volume of the babies did not correlate with their mother's age, socioeconomic status, parity, or fish consumption, or with their gestational age or birth weight. Correlations were sought for between the mother's UI when collected at various times (third trimester and 3 days and 3 months after delivery) and the thyroid volume during and after pregnancy, the iodine content in breast milk at 3 days and 3 months after delivery, and offspring's neonatal TSH, thyroid volume, and UI. Significant but weak correlations were found for mother's UI 3 months after delivery and the infant's UI at 3 months $(R=0.42$, $p<0.05)$, breast milk content 3 days after delivery and infant's $\mathrm{UI}$ at 3 days $(R=0.51, p<0.05)$, and breast milk content 3 months after delivery and the infant's UI at 3 months $(R=0.44, p<0.05)$.

\section{Discussion}

The data presented in this study clearly show that Portuguese women of the Minho region and their progeny have a UI concentration strongly indicative of ID, as defined by criteria established by the WHO (1-4). In all groups $(61 \%$ of nonpregnant, $76-91 \%$ of women throughout pregnancy, $66-92 \%$ after pregnancy, $62 \%$ of the newborns, and $52 \%$ of the infants) the median UI was under the newly accepted values that are considered desirable. These are above $100 \mu \mathrm{g} / \mathrm{L}$ for the general population, for lactating women, and for children under 2 years of age, and 150-249 $\mu \mathrm{g} / \mathrm{L}$ throughout pregnancy. Moreover, the percentage of samples with $\mathrm{U}<50 \mu \mathrm{g} / \mathrm{L}$ was higher than 20, the accepted percentage for an iodinesufficient population. It was 36 for nonpregnant women, 28-38 for pregnant women, 49-60 for women after delivery, 32 for newborns, and 21 for infants. These results are similar to others found in iodine-deficient areas (11-18).

The reductions in UI concentrations noted in this study are undoubtedly due to insufficient iodine intake, probably due to the lack of a policy of universal salt iodination in Portugal and from the absence of general medical advice on supplementing pregnant and lactating women with iodine. In addition, despite the proximity to the sea, the Portuguese population of the Minho region, particularly in the lower socioeconomic classes, has a low fish-consumption rate as revealed by the food questionnaire (19). Even when fish is included in the diet, its content of iodine may depend on whether it originates from the sea or from farms. Of note, unexpected ID has been observed in other coastal areas $(1-3,16)$.

While urinary iodine excretion is the most appropriate indicator for assessing recent iodine intake in epidemiological studies, other indices such as goiter are clinical hallmarks of ID (1-3,20-26). In our study almost $14 \%$ of all pregnant women had gestational goiter, and heterogeneous echotexture patterns after pregnancy were often observed. This is in agreement with reports from other iodine-insufficient populations (23-25). In addition, the thyroid volume during pregnancy correlated with that observed after pregnancy, indicating that thyroid enlargement only partially reverted after delivery. This observation provides additional evidence for ID. Unlike other studies, we did not find any relation between thyroid volume and age, previous pregnancies, socioeconomic status, urinary or breast milk iodine, or the progeny's thyroid volume (21-26), but only with the fishconsumption rate (25).

Iodine insufficiency was also reflected in the data for breast milk iodine concentrations obtained in this study. This is particularly relevant to the complications of ID because breast milk is usually the only source of iodine for newborns. Breast milk iodine is considered sufficient when values are in the range of $150-180 \mu \mathrm{g} / \mathrm{L}(4,11,14,17,18,27-35)$. The median iodine content in breast milk was lower than this in our study. Similarly to other published data, we also observed a positive correlation between the iodine content of breast milk and that of the nursing infant's urine (27-35). Considering that all of the women were breast-feeding on day 3 and $58 \%$ were doing so 3 months later, a high percentage of the infant population in the study area were probably not getting adequate iodine for thyroid hormone synthesis and storage (31-34). In fact, assuming a daily intake of $150 \mathrm{~mL} / \mathrm{kg}$ (about $500 \mathrm{~mL}$ milk for the newborns and $750 \mathrm{~mL}$ for 3-month-old infants), these babies were getting about half of the recommended daily dose of iodine $(1-3,31,35)$. Notably, infants taking formula milk at 3 months had a median UI significantly higher than breastfed infants (137 vs. $80 \mu \mathrm{g} / \mathrm{L}$ ). This could be due either to higher iodine content or to lower bioavailability of iodine in formula milk compared to breast milk or a combination of the two $(11,28,34)$.

The best criteria for assessing the degree of ID in newborns have not been established because of lack of sufficient data for UI in this group. Other potential indices of ID, such as neonatal TSH, are not completely reliable due to many factors, including the timing of sample collection (1-4,32, 35,36). Although the present study showed that the newborns met the WHO criteria for desirable serum TSH concentrations (considered iodine sufficient if less than $3 \%$ of the newborns have $\mathrm{TSH}>5 \mathrm{mU} / \mathrm{L}$ ), it is now well recognized that the regulation of TSH secretion in the newborn does not follow the same feedback mechanisms observed when the thyroid-pituitary axis is fully developed (6). Therefore, the cutoffs for defining severity of ID on the basis of newborn TSH concentrations originally proposed by the WHO have been questioned and are not considered in most of the recent recommendations (3).

Another proposed indicator of ID is the thyroid volume. In the present study, when adjusted for sex, age, and body surface, we found a relatively high percentage of children with thyroid volumes above the 75 th percentile $(37,38)$. These 
results were not expected because the development of neonatal goiter from intrauterine iodine restriction is believed to be prevented by a prenatal iodine intake that results in neonatal UI higher than $50 \mu \mathrm{g} / \mathrm{L}$ (39) as was observed in the present case study.

In summary, our data suggest that pregnant and lactating women of the Minho region are iodine deficient. This may compromise the proper development of their offspring, and impact adversely on the psychomotor and intellectual performance of future generations. The WHO technical commission published, last December, a consensus about the strategy to eliminate IDD (18). According to this and to other recommendations (40), considering the lack of reliable information regarding iodine nutrition from other areas, and based on the results presented here, we strongly recommend that all Portuguese pregnant and lactating women, as well as women of fertile age, receive iodine supplements.

\section{Acknowledgments}

We are grateful to Dr. Laura Vilarinho and Dr. Rui Vaz Osório, Instituto de Genética Médica Jacinto Magalhões and Instituto Nacional de Saúde, Porto, Portugal, for providing information on the newborn TSH concentration, as measured within the National Screening Program for Congenital Hypothyroidism, and to Ms. Socorro Durán, Ms. M. Jesús Presas, and Ms. Elena Fernández for their technical help with the urinary and milk iodine determinations.

This study was supported by the Portuguese Science Foundation (FCT)-FEDER Grant POCTI_PSI_60948_2004 and by the Integrated Actions for exchange of scientists "PortugalSpain E-84/2006."

\section{Disclosure Statement}

M.J.C., S.A., J.A.P., and G.M.E. planned and conducted the research, discussed the data, and drafted the manuscript. P.O. conducted the statistical analysis together with the other authors. J.A.P. is the principal investigator of the project that funded this research. None of the authors had conflict of interest to report. No competing financial interests exist.

\section{References}

1. World Health Organization 2007 Assessment of Iodine Deficiency Disorders and Monitoring Their Elimination. A Guide for Programme Managers. Third edition. World Health Organization, Geneva.

2. de Benoist B, Andersson M, Egli I, Takkouche B, Allen H (eds) 2004 Iodine Status Worldwide: WHO Global Database on Iodine Deficiency. Department of Nutrition for Health and Development, World Health Organization, Geneva.

3. Andersson M, de Benoist B, Darnton-Hill I, Delange F (eds) 2007 Iodine Deficiency in Europe: A Continuing Public Health Problem. World Health Organization, Geneva.

4. Delange F 2007 Iodine requirements during pregnancy, lactation and the neonatal period and indicators of optimal iodine nutrition. Public Health Nutr 10:1571-1580.

5. de Escobar GM, Obregón MJ, del Rey FE 2004 Maternal thyroid hormones early in pregnancy and fetal brain development. Best Pract Res Clin Endocrinol Metab 18:225-248.

6. de Escobar GM, Obregón MJ, del Rey FE 2007 Iodine deficiency and brain development in the first half of pregnancy. Public Health Nutr 10:1554-1570.
7. Morreale de Escobar G, Obregón MJ, Escobar del Rey F 2000 Is neuropsychological development related to maternal hypothyroidism or to maternal hypothyroxinemia? J Clin Endocrinol Metab 85:3975-3987.

8. Hetzel BS 2000 Iodine and neuropsychological development. J Nutr 130:493s-495s.

9. Glinoer D 1997 The regulation of thyroid function in pregnancy: pathways of endocrine adaptation from physiology to pathology. Endocr Rev 18:404-433.

10. Graffar M 1956 Une methode de classification social d'echantillons de la population. Courrier 6:445-459.

11. Zimmermann MB 2007 The impact of iodised salt or iodine supplements on iodine status during pregnancy, lactation and infancy. Public Health Nutr 10:1584-1595.

12. Hollowell JG, Haddow JE 2007 The prevalence of iodine deficiency in women of reproductive age in the United States of America. Public Health Nutr 10:1532-1539.

13. Caldwell KL, Jones R, Hollowell JG 2005 Urinary iodine concentration: United States National Health And Nutrition Examination Survey 2001-2002. Thyroid 15:692-699.

14. Pearce EN 2007 National trends in iodine nutrition: is everyone getting enough? Thyroid 17:823-827.

15. Stilwell G, Reynolds PJ, Parameswaran V, Blizzard L, Greenaway TM, Burgess JR 2008 The influence of gestational stage on urinary iodine excretion in pregnancy. J Clin Endocrinol Metab 93:1737-1742.

16. Laurberg P, Jorgensen $T$, Perrild H, Ovesen L, Knudsen N, Pedersen IB, Rasmussen LB, Carlé A, Vejbjerg P 2006 The Danish investigation on iodine intake and thyroid disease, Dan Thyr: status and perspectives. Eur J Endocrinol 155:219-228.

17. Zimmermann MB 2007 The adverse effects of mild-tomoderate iodine deficiency during pregnancy and childhood: a review. Thyroid 17:829-835.

18. WHO Secretariat, Andersson M, de Benoist B, Delange F, Zupan J 2007 Prevention and control of iodine deficiency in pregnant and lactating women and in children less than 2-years-old: conclusions and recommendations of the Technical Consultation. Public Health Nutr 10:1606-1611.

19. Moreira PA, Padrão PD 2004 Educational and economic determinants of food intake in Portuguese adults: a crosssectional survey. BMC Public Health 4:58.

20. Laurberg P, Andersen S, Bjarnadóttir RI, Carlé A, Hreidarsson AB, Knudsen N, Ovesen L, Pedersen IB, Rasmussen LB 2007 Evaluating iodine deficiency in pregnant women and young infants-complex physiology with a risk of misinterpretation. Public Health Nutr 10:1547-1552.

21. Berghout A, Wiersinga W 1998 Thyroid size and thyroid function during pregnancy: an analysis. Eur J Endocrinol 138: 536-542.

22. Smyth PP, Hetherton AM, Smith DF, Radcliff M, O'Herlihy C 1997 Maternal iodine status and thyroid volume during pregnancy: correlation with neonatal iodine intake. J Clin Endocrinol Metab 82:2840-2843.

23. Kung AW, Chau MT, Lao TT, Tam SC, Low LC 2002 The effect of pregnancy on thyroid nodule formation. J Clin Endocrinol Metab 87:1010-1014.

24. Rotondi M, Sorvillo F, Mazziotti G, del Buono A, Nicchio MR, Balzano S, Bellastrella A, Glinoer D, Carella C 2002 The influence of parity on multinodular goiter prevalence in areas with moderate iodine deficiency. J Endocrinol Invest 25:442-446.

25. Valentino R, Savastano S, Tommaselli AP, Di Biase S, Calvanese E, Carbone D, Dorato M, Orio Jr F, Lupoli G, Lombardi G 2004 Screening a coastal population in Southern Italy: iodine deficiency and prevalence of goitre, nutritional 
aspects and cardiovascular risk factors. Nutr Metab Cardiovasc Dis 14:15-19.

26. Glinoer D, Lemone M, Bourdoux P, De Nayer P, Delange F, Kinthaert J, Lejeune B 1992 Partial reversibility during late postpartum of thyroid abnormalities associated with pregnancy. J Clin Endocrinol Metab 74:453-457.

27. Bader N, Möller U, Leiterer M, Franke K, Jahreis G 2005 Pilot study: tendency of increasing iodine content in human milk and cow's milk. Exp Clin Endocrinol Diabetes 113:8-12.

28. Dorea JG 2002 Iodine nutrition and breast feeding. J Trace Elem Med Biol 16:207-220.

29. Ardawi MSM, Nasrat HA, Mustafa BE 2002 Urinary iodine excretion and maternal thyroid function. During pregnancy and postpartum. Saudi Med J 23:413-422.

30. Ordookhani A, Pearce EN, Hedayati M, Mirmiran P, Salimi S, Azizi F, Braverman LE 2007 Assessment of thyroid function and urinary and breast milk iodine concentrations in healthy newborns and their mothers in Tehran. Clin Endocrinol 67:175-179.

31. Ares S, Quero J, Durán S, Presas MJ, Herruzo R, Morreale de Escobar G 1994 Iodine content of infant formulas and iodine intake of premature babies: high risk of iodine deficiency. Arch Dis Child Fet Neonat Ed 71:F184-F191.

32. Travers CA, Guttikonda K, Norton CA, Lewis PR, Mollart LJ, Wiley V, Wilcken B, Eastman CJ, Boyages SC 2006 Iodine status in pregnant women and their newborns: are our babies at risk of iodine deficiency? Med J Aust 184:617-620.

33. Ares S, Quero J, Morreale de Escobar G 2005 Neonatal iodine deficiency: clinical aspects. J Pediatr Endocrinol Metab 18:1257-1264.

34. Smyth PP, Smith DF, Sheehan S, Higgins M, Burns R, O'Herlihy C 2007 Short-term changes in maternal and neonatal urinary iodine excretion. Thyroid 17:219-222.
35. Chan SS, Hams G, Wiley V, Wilcken B, McElduff A 2003 Postpartum maternal iodine status and the relationship to neonatal thyroid function. Thyroid 13:873-876.

36. Sullivan KM, May W, Nordenberg D, Houston R, Maberly GF 1997 Use of thyroid stimulating hormone testing in newborns to identify iodine deficiency. J Nutr 127:55-58.

37. Ares S, Pastor I, Quero J, Morreale de Escobar G 1995 Thyroid complications, including overt hypothyroidism, related to the use of non-radiopaque silastic catheters for parenteral feeding in prematures requiring injection of small amounts of an iodinated contrast medium. Acta Paediatr 84:579-581.

38. Varlas V, Gheorghin M 2006 Fetal thyroid status in normal pregnancy and premature birth in euthyroid women without goiter from areas with or without iodine deficiency. Acta Endocrinol 4:403-418.

39. Delange F, Burgi H 1989 Iodine deficiency disorders in Europe. Bull World Health Organ 67:317-325.

40. Berbel P, Obregón MJ, Bernal J, Escobar del Rey F, Morreale de Escobar G 2007 Iodine supplementation during pregnancy: a public health challenge. Trends Endocrinol Metab 18:338-343.

Address reprint requests to: Joana A. Palha, Ph.D.

Life and Health Sciences Research Institute (ICVS) School of Health Sciences

University of Minho

Campus Gualtar

4710-057 Braga

Portugal

E-mail: japalha@ecsaude.uminho.pt 
